\title{
Ethnic differences translate to inadequacy of high-risk screening for gestational diabetes mellitus in an Asian population: a cohort study
}

\author{
Yap-Seng Chong ${ }^{1,4^{*}}$, Shirong Cai ${ }^{1}$, Harvard Lin ${ }^{1}$, Shu E Soh ${ }^{2,3}$, Yung-Seng Lee ${ }^{3}$, Melvin Khee-Shing Leow ${ }^{4,5,6}$, \\ Yiong-Huak Chan ${ }^{7}$, Li Chen ${ }^{4}$, Joanna D Holbrook ${ }^{4}$, Kok-Hian Tan ${ }^{8}$, Victor Samuel Rajadurai ${ }^{9}$, \\ George Seow-Heong Yeo ${ }^{10}$, Michael S Kramer ${ }^{1,11}$, Seang-Mei Saw ${ }^{2}$, Peter D Gluckmann ${ }^{4,12}$, Keith M Godfrey ${ }^{13,14}$, \\ and Kenneth Kwek ${ }^{10}$ on behalf of the GUSTO study group
}

\begin{abstract}
Background: Universal and high-risk screening for gestational diabetes mellitus (GDM) has been widely studied and debated. Few studies have assessed GDM screening in Asian populations and even fewer have compared Asian ethnic groups in a single multi-ethnic population.

Methods: 1136 pregnant women (56.7\% Chinese, 25.5\% Malay and 17.8\% Indian) from the Growing Up in Singapore Towards healthy Outcomes (GUSTO) birth cohort study were screened for GDM by 75-g oral glucose tolerance test (OGTT) at 26-28 weeks of gestation. GDM was defined using the World Health Organization (WHO) criteria. High-risk screening is based on the guidelines of the UK National Institute for Health and Clinical Excellence.

Results: Universal screening detected significantly more cases than high-risk screening [crude OR 2.2 (95\% Cl 1.7-2.8)], particularly for Chinese women [crude $\mathrm{OR}=3.5(95 \% \mathrm{Cl} 2.5-5.0)$ ]. Pre-pregnancy BMI $>30 \mathrm{~kg} / \mathrm{m}^{2}$ (adjusted $\mathrm{OR}=3.4,95 \%$ $\mathrm{Cl} 1.5-7.9$ ) and previous GDM history (adjusted $\mathrm{OR}=6.6,95 \% \mathrm{Cl} 1.2-37.3$ ) were associated with increased risk of GDM in Malay women while GDM history was the only significant risk factor for GDM in Chinese women (adjusted OR=4.7, 95\% Cl 2.0-11.0).

Conclusion: Risk factors used in high-risk screening do not sufficiently predict GDM risk and failed to detect half the GDM cases in Asian women. Asian women, particularly Chinese, should be screened to avoid under-diagnosis of GDM and thereby optimize maternal and fetal outcomes.
\end{abstract}

Keywords: Universal screening, High risk screening, Gestational diabetes, Asians, Ethnic

\section{Background}

Gestational diabetes mellitus (GDM), even when mild, can have adverse consequences on the health of both mother and child during pregnancy and early postpartum period $[1,2]$. Women with GDM have increased risk of GDM

\footnotetext{
* Correspondence: obgcys@nus.edu.sg

'Department of Obstetrics \& Gynaecology, Yong Loo Lin School of Medicine, National University of Singapore, National University Health System, 1 E Kent Ridge Road, NUHS Tower Block, Singapore 119228, Singapore

${ }^{4}$ Singapore Institute for Clinical Sciences, Agency for Science and Technology Research (A*STAR), Brenner Center for Molecular Medicine, 30 Medical Drive, Singapore 117609, Singapore

Full list of author information is available at the end of the article
}

recurrence in subsequent pregnancies [3-5], and of overt type 2 diabetes mellitus $[4,6]$, while infants born to mothers with GDM are at increased risk of developing obesity and diabetes in later life [7]. Studies have shown that screening, detection and management of GDM can mitigate the risk of adverse outcomes and metabolic diseases in both mother and child [8-10]. The development of GDM may thus be an indicator of subsequent metabolic risk that requires identification and appropriate management.

Factors such as family history of diabetes mellitus, maternal obesity, age $>30$ years and GDM in previous pregnancies have been reported to increase the risk of GDM 
[11]. Although the diagnostic criteria are still debated, the oral glucose tolerance test (OGTT) is generally recognized as the 'gold standard' for diagnosis of GDM [12].

It is controversial whether screening for GDM with an OGTT in pregnant women should be universal (testing all pregnancies) or selective (testing only pregnant women with risk factors for GDM) [13,14]. American Diabetes Association, American College of Obstetricians and Gynecologists, UK National Institute for Health and Clinical Excellence (NICE) recommend screening in women with known risk factors [15-17] while other organizations like International Association of Diabetes and Pregnancy Study Groups (IADPSG) support universal screening at 26-28 weeks gestation [18]. Results from several studies indicate that universal screening for GDM in certain populations is more sensitive and cost-effective $[14,19,20]$, especially in terms of preventing future type 2 diabetes.

Asians are at greater risk of GDM compared to their Caucasian counterparts [21,22]. In Singapore, the three major ethnic groups are all Asian: Chinese, Malay and Indian. These three ethnicities jointly comprise over $40 \%$ the global population [23]. To the best of our knowledge, our study is the first to include these three ethnic groups in a single cohort and to compare the proportion of GDM using universal versus selective (high-risk for GDM) screening among them.

\section{Methods}

Pregnant women 18 years and above, who were in their first trimester were recruited from the KK Women's and Children's Hospital $(\mathrm{KKH})$ and National University Hospital (NUH) in Singapore between June 2009 and September 2010 to participate in the Growing Up in Singapore Towards healthy Outcomes (GUSTO) birth cohort study. Our study included singletons and multiple pregnancies but only for the pregnancy when they were recruited. These women were either Singapore citizens or permanent residents from three different ethnic groups with homogenous parental ethnic background (both parents of the same ethnic group): Chinese, Malay, and Indian. Women who were on chemotherapy, psychotropic drugs or those with type 1 diabetes were excluded [24]. Demographic data, family and obstetric history of the subjects were obtained from interviewer-administered questionnaires at the time of enrolment. Maternal prepregnancy weight was self-reported. The study received approval from Institutional Review Board (IRB) that reviews ongoing research in $\mathrm{KKH}$ and NUH (Centralized Institutional Review Board and Domain Specific Review Board respectively). Informed written consent was obtained from each participant.

Testing for GDM was performed using a 75 -g oral glucose tolerance test after overnight fasting ( 8 to 10 hours) at 26-28 weeks gestation. The 1999 World Health Organization (WHO) standard criteria were selected for the study define GDM: $\geq 7.0 \mathrm{mmol} / \mathrm{L}$ for fasting glucose and/or $\geq 7.8 \mathrm{mmol} / \mathrm{L}$ for 2 -hour post-glucose $[25,26]$ as blood glucose levels were only collected twice (fasting and 2-hour post-glucose) for our study, to minimize subject burden. Women with GDM were subsequently managed according to standard protocols practiced across both hospitals.

Participants were stratified according to risk factors for GDM to compare the performance of a high-risk screening approach to universal screening for detecting GDM. Subjects were categorized as high-risk for GDM based on the guidelines recommended by UK NICE if they fell into one or more of the following categories: (1) obese [body mass index (BMI) of $>30.0 \mathrm{~kg} / \mathrm{m}^{2}$ ], (2) family history of type 2 diabetes (first-degree relative), (3) GDM in a previous pregnancy, (4) previous delivery of a baby with a birth weight of $\geq 4.5 \mathrm{~kg}$ or (5) ethnic origin with known high prevalence of diabetes (South Asians, black Caribbean, Middle Eastern) [17]. As South Asian includes anyone of family origin from India, Pakistan or Bangladesh, all Indian subjects were classified as high-risk.

The McNemar chi-square test was performed to compare the prevalence of detected GDM based on universal versus high-risk screening using. Ordinary chi-square test was utilized to compare the prevalence of detected GDM across the ethnic groups. Logistic regression was used to calculate the odds of GDM associated with each of the risk factors used in high-risk screening. The odds ratios for comparison across ethnic groups, were further adjusted for pre-pregnancy BMI $>30 \mathrm{~kg} / \mathrm{m}^{2}$, family history of diabetes, previous history of GDM and macrosomia. Kruskal Wallis and Mann-Whitney U tests were applied to examine differences in quantitative variables, and chisquare test for categorical variables. There are missing data on covariates [pre-pregnancy BMI (8.9\%), family history of diabetes (2.7\%), previous history of births $\geq 4.5 \mathrm{~kg}$ (3.2\%) and GDM (3.1\%)]. Multiple imputations of these variables using Chained Equations imputation (20 imputations) yielded very similar findings (data available upon request). As such, missing data on covariates were excluded from the analysis. All analyses were carried out using SPSS version 20.0 (IBM, Armonk, NY, USA).

\section{Results}

From June 2009 to September 2010, 1247 women were enrolled in GUSTO birth cohort. Of these, 1136 (91.1\%) received the OGTT at 26-28 weeks gestation; the remaining 111 subjects either declined OGTT or missed their 26-28 weeks clinic visit. No significant differences were found between the 1136 women who had OGTTs and the 111 women who did not have OGTT in terms of ethnicity (with OGTT- 56.7\% Chinese, 25.5\% Malay and 17.8\% 
Indian; without OGTT- 54.3\% Chinese, 24.8\% Malay, 20.1\% Indian), age (mean $\pm \mathrm{SD}, 30.7 \pm 5.1$ vs $30.6 \pm 5.8$ years), parity ( $46.0 \%$ vs $40.2 \%$ primiparous), pre-pregnancy BMI $\left(22.7 \pm 4.4 \mathrm{vs} 22.8 \pm 4.6 \mathrm{~kg} / \mathrm{m}^{2}\right)$, previous history of GDM (3.4\% vs $5.6 \%$ ), family history of diabetes $(29.4 \%$ vs $23.9 \%)$ as well as previous births $\geq 4.5 \mathrm{~kg}$ ( $0.3 \%$ for both). The demographic and clinical characteristics of all 1136 participants who completed the 75-g OGTT are summarized in Table 1. The predominant ethnic group was Chinese (56.7\%), followed by Malay (25.5\%) and Indian (17.8\%). We oversampled Malay and Indian participants in order to have ample statistical power to study the effect of ethnicity. The Chinese women in this study were older and less obese compared to the Malay and Indian women. They were also more likely to be primiparous and less likely to have family history of diabetes.

When the NICE guidelines for high-risk screening were applied to GUSTO, 496 of the 1136 participants who underwent OGTT, were classified as high-risk. Universal screening detected a higher proportion of GDM $(18.9 \%, \mathrm{n}=215)$ than high-risk screening $(9.8 \%, \mathrm{n}=111)$ (Table 2). In other words, if OGTT had been performed only in women considered high-risk by the NICE guidelines, almost half of the women with GDM would have been missed.

As shown in Table 2, universal screening resulted in GDM prevalence of $21.0 \%, 12.1 \%$ and $22.3 \%$ in Chinese, Malay and Indian women respectively. GDM risk based on universal screening remained higher in Chinese (adjusted $\mathrm{OR}=2.2,95 \%$ CI 1.4-3.4) and Indian (adjusted $\mathrm{OR}=2.2$, 95\% CI 1.3 -3.6) women relative to Malay women, after
Table 2 Proportion of detected gestational diabetes mellitus (GDM) in GUSTO cohort using universal versus high-risk screening ${ }^{a}$

\begin{tabular}{lcccc}
\hline $\begin{array}{l}\text { Screening } \\
\text { methods }\end{array}$ & $\begin{array}{c}\text { Whole cohort } \\
(\mathbf{n}=\mathbf{1 1 3 6 )}\end{array}$ & $\begin{array}{c}\text { Chinese } \\
(\mathbf{n}=\mathbf{6 4 4})\end{array}$ & $\begin{array}{c}\text { Malay } \\
\mathbf{( n = 2 9 0 )}\end{array}$ & $\begin{array}{c}\text { Indian } \\
(\mathbf{n}=\mathbf{2 0 2})\end{array}$ \\
\hline Universal $^{\mathrm{b}}$ & $215(18.9)$ & $135(21.0)$ & $35(12.1)$ & $45(22.3)$ \\
High-risk $^{\mathrm{b}}$ & $111(9.8)^{\mathrm{c}}$ & $45(7.0)^{\mathrm{c}}$ & $21(7.2)^{\mathrm{c}}$ & $45(22.3)$ \\
\hline
\end{tabular}

${ }^{a}$ Values are given as number (\%).

buniversal screening is where all participants undergo oral glucose tolerance test (OGTT); High-risk screening is where only participants with one or more of the risk factors based on the guidelines from UK National Institute for Health and Clinical Excellence (NICE) have to undergo OGTT.

${ }^{\mathrm{c}} \mathrm{P}<0.001$ compared to Universal Screening.

adjusting for non-ethnicity related risk factors (Additional file 1: Table S1). Overall sensitivity and specificity of high-risk screening were $51.6 \%$ and $52.2 \%$ respectively (Additional file 1: Table S2). Sensitivity of high-risk screening is $33.3 \%$ in Chinese and $60.0 \%$ in Malay; specificity is $74.1 \%$ and $62.4 \%$ respectively in Chinese and Malay women. Indian women were all classified high-risk by NICE guidelines because of their South Asian origin.

Pre-pregnancy BMI $>30 \mathrm{~kg} / \mathrm{m}^{2}(\mathrm{OR}=3.3,95 \% \mathrm{CI} 1.5-7.6)$ and previous GDM history ( $\mathrm{OR}=7.6,95 \% \mathrm{CI} 1.5$ - 39.2) were associated with increased risk of GDM in Malay women, even after adjusting for all other risk factors (Table 3). In Chinese women, only previous history of GDM was associated with increased GDM risk (adjusted OR $=4.7,95 \%$ CI 2.0-11.0) while none of the non-ethnic risk factors was significantly associated with GDM risk in Indians. Indian ethnic origin was associated with a non-significant increase in GDM risk [adjusted OR $=1.25(95 \% \mathrm{CI} 0.84-1.86)]$. If the

Table 1 Maternal demographic and clinical characteristics of participants completing the 75-g oral glucose tolerance test ${ }^{\mathrm{a}}$

\begin{tabular}{|c|c|c|c|c|}
\hline & \multicolumn{3}{|c|}{ Total $(n=1136)$} & \multirow{2}{*}{ P value } \\
\hline & Chinese $(n=644)$ & Malay $(n=290)$ & Indian $(n=202)$ & \\
\hline Maternal age, y & $31.7 \pm 4.9$ & $29.0 \pm 5.5$ & $29.7 \pm 4.6$ & $<0.001$ \\
\hline Primiparous & $308(47.8 \%)$ & $116(40.0 \%)$ & $73(36.1 \%)$ & 0.005 \\
\hline Pre-pregnancy BMl, kg/m² & $21.6 \pm 3.4$ & $24.4 \pm 5.6$ & $23.9 \pm 4.4$ & $<0.001$ \\
\hline $\mathrm{BMI}>30 \mathrm{~kg} / \mathrm{m}^{2}$ & $17(2.6 \%)$ & $41(14.1 \%)$ & $18(8.9 \%)$ & $<0.001$ \\
\hline BMI $25-30 \mathrm{~kg} / \mathrm{m}^{2}$ & $68(10.6 \%)$ & $64(22.0 \%)$ & $49(24.3 \%)$ & \\
\hline $\mathrm{BMl}<25 \mathrm{~kg} / \mathrm{m}^{2}$ & $501(77.8 \%)$ & $158(54.5 \%)$ & $119(58.9 \%)$ & \\
\hline Missing data & $58(9.0 \%)$ & $27(9.3 \%)$ & $16(7.9 \%)$ & \\
\hline Family history of diabetes mellitus & $156(24.8 \%)$ & $87(31.0 \%)$ & $91(46.7 \%)$ & $<0.001$ \\
\hline Previous history of GDM & $24(3.8 \%)$ & $6(2.1 \%)$ & $9(4.6 \%)$ & 0.288 \\
\hline Previous birth $\geq 4.5 \mathrm{~kg}$ & $3(0.5 \%)$ & $1(0.4 \%)$ & $0(0 \%)$ & 0.626 \\
\hline One or more NICE risk factors except ethnicity & $177(27.5 \%)$ & $117(40.3 \%)$ & $101(50.0 \%)$ & $<0.001$ \\
\hline Fasting plasma glucose $\geq 7.0 \mathrm{mmol} / \mathrm{L}$ & $1(0.2 \%)$ & $3(1.0 \%)$ & $1(0.5 \%)$ & 0.170 \\
\hline $2 \mathrm{~h}$ post OGTT Plasma glucose $\geq 7.8 \mathrm{mmol} / \mathrm{L}$ & $135(21.0 \%)$ & $34(11.7 \%)$ & $45(22.3 \%)$ & 0.001 \\
\hline
\end{tabular}

Abbreviations: BMI, Body Mass Index; GDM, gestational diabetes mellitus; NICE, UK National Institute for Health and Clinical Excellence; OGTT, oral glucose tolerance test.

${ }^{a}$ Values are given as $\mathrm{n}(\%)$ or mean $\pm \mathrm{SD}$.

*Analysed by Kruskal-Wallis test and chi-square test for qualitative variables categorical variables, respectively. 
Table 3 Ratios for associations between gestational diabetes mellitus and risk factors among the three ethnic groups

\begin{tabular}{|c|c|c|c|c|c|c|}
\hline \multirow[t]{2}{*}{ Risk factor } & \multicolumn{3}{|c|}{ Unadjusted odds ratio $(95 \% \mathrm{Cl})$} & \multicolumn{3}{|c|}{ Adjusted odds ratios $(95 \% \mathrm{Cl})^{a}$} \\
\hline & Chinese & Malay & Indian & Chinese & Malay & Indian \\
\hline Pre-pregnancy $\mathrm{BMI}>30 \mathrm{~kg} / \mathrm{m}^{2}$ & $2.7(1.0-7.2)$ & $3.3(1.5-7.6)^{b}$ & $1.8(0.6-5.0)$ & $2.4(0.8-6.8)$ & $3.4(1.5-7.9)^{b}$ & $1.8(0.6-5.1)$ \\
\hline Family history of diabetes & $1.0(0.6-1.5)$ & $1.6(0.8-3.3)$ & $1.2(0.6-2.3)$ & $0.8(0.5-1.3)$ & $1.6(0.7-3.5)$ & $1.2(0.6-2.5)$ \\
\hline Previous history of GDM & $4.8(2.1-11.0)^{b}$ & $7.6(1.5-39.2)^{b}$ & $3.0(0.8-11.6)$ & $4.7(2.0-11.0)^{b}$ & $6.6(1.2-37.3)^{b}$ & $2.8(0.7-11.0)$ \\
\hline Previous birth $\geq 4.5 \mathrm{~kg}$ & $1.9(0.2-20.9)$ & Not calculable* & Not calculable* & $3.9(0.2-62.9)$ & Not calculable* & Not calculable* \\
\hline
\end{tabular}

Abbreviations: BMI, Body Mass Index; GDM, gestational diabetes mellitus.

${ }^{a}$ Adjusted for other risk factors including pre-pregnancy BMI $>30 \mathrm{~kg} / \mathrm{m}^{2}$, family history of diabetes, previous history of GDM or birth weight $\geq 4.5 \mathrm{~kg}$.

${ }^{\mathrm{b}} \mathrm{P}<0.05 *$ Insufficient number of previous birth $\geq 4.5 \mathrm{~kg}$ to calculate.

pre-pregnancy BMI cut-off was revised to $>25 \mathrm{~kg} / \mathrm{m}^{2}$ to include the overweight women, it is found to be associated with increased risk of GDM in both Chinese (adjusted OR $=2.0,95 \% \mathrm{CI} 1.2-3.3$ ) and Malay (adjusted $\mathrm{OR}=3.3,95 \%$ CI 1.5-7.1) women (data not shown in table). In addition, maternal age ( $>25$ years) was found to be associated with increased GDM risk only in Malay women (adjusted OR $=7.7,95 \%$ CI 1.01-58.6) (data not shown in table).

In this cohort, only $0.4 \%$ of the mothers were diagnosed positive for GDM based on the fasting glucose WHO cut-off, compared to $18.5 \%$ with the 2-hour post-glucose cut-off. The low diagnosis rate with the fasting glucose was consistent across all the ethnic groups $(0.2 \%, 1.0 \%$ and $0.5 \%$ in Chinese, Malay and Indian women respectively).

\section{Discussion}

Universal screening at 26-28 weeks gestation in a population of Singaporean women of Chinese, Malay and Indian ethnic origin, detected almost twice as many GDM cases as a high-risk screening approach based on the NICE guidelines. Individual risk factors used in high-risk screening showed poor sensitivity for GDM risk, particularly among Indian women, in whom none of the risk factors was associated with a significant increase in GDM risk. Previous history of GDM significantly increased risk of GDM in both Malay and Chinese women, but it is important to note that many of these women $(47.8 \%$ and $40.0 \%$ in Chinese and Malay women respectively) were primiparous. While other studies have also shown that risk factors are not independent predictors of GDM $[27,28]$ in Asian populations, they have not compared these predictors among distinct Asian ethnic groups.

Using the WHO criteria, the majority of GDM cases were detected by the $2 \mathrm{~h}$ post-glucose levels across all three ethnic groups in this cohort. Fasting glucose levels were relatively low (mean $=4.37 \mathrm{mmol} / \mathrm{L}$, standard deviation $=0.54$ ) whereas $2 \mathrm{~h}$ post-glucose levels $($ mean $=6.57 \mathrm{mmol} / \mathrm{L}$, standard deviation $=1.61)$ were higher than those reported in other ethnicities (South Asian, Middle Eastern, Pacific Islander and Anglo-European) [29]. Monnier et al. [30] previously reported that the mean glycemic control was predominantly contributed by postprandial glucose level in patients with mild diabetes compared to standard type 2 diabetes where the fasting plasma glucose contributed more to the glycemic control. This may imply that the GDM observed in our population was a milder form of diabetes which was more effectively picked up with the $2 \mathrm{~h}$ post-glucose levels.

Many studies have reported a strong association between maternal obesity and the development of GDM [31-34]. In our cohort, Malay women had a higher rate of obesity than Indian or Chinese women. Yet universal testing indicated that Malay women had a lower prevalence of GDM compared to either of the other two ethnic groups. The reasons for this finding are unclear but we speculate that it may be related to the differential distribution of adipose tissue in different ethnic groups [35] and/or differences in insulin resistance and $\beta$-cell function [36,37]. In view of these substantial physiological differences across the ethnic groups, high-risk screening will not work well in detecting GDM in a multi-ethnic Asian population like Singapore.

The main strength of our study is the inclusion of three Asian ethnic groups in our cohort. These ethnic groups reflect more than $40 \%$ of the global population [23]. While many studies have compared universal and high-risk screening for GDM, few have been conducted in Asian populations and none has compared the three ethnic groups included in our study. One limitation of our study is the lack of $1 \mathrm{~h}$ post-OGTT plasma glucose reading, hence we used the 1999 WHO diagnostic criteria instead of the revised 2013 WHO diagnostic criteria [38]. We also acknowledge that our cohort may not be representative of the Singapore population, as the participants were recruited from only two hospitals. However, those are the two largest maternity hospitals in the country and included both private and subsidised patients. Selection bias may therefore influence the prevalence of GDM observed among study participants but should not bias associations between GDM and ethnicity or any other risk factors. Another limitation is that pre-pregnancy BMI was self-reported as participants were already pregnant at enrolment. Finally, we were unable to examine the possible consequences of 
missed GDM detection, because (for ethical reasons) every GDM case was referred for treatment.

Our findings suggest that clinical risk factors used in defining high-risk population are poorly sensitive for predicting GDM risk in the ethnic groups studied, particularly for Chinese women. More than half of the GDM cases would have been missed if high-risk screening was used. Universal testing appears more appropriate for detecting GDM in Asian populations. Although Indian women are known to be at greater risk of GDM, routine screening of Indian women is still not widely practiced in Asia. With increasing migration of Asians to countries like Australia, United States, Canada and United Kingdom, our findings have important implications for screening strategies in those countries as well [39].

Beneficial effects have been reported on both maternal and fetal outcomes with detection and treatment of even mild GDM [40-45]. Crowther et al. [40] demonstrated that mothers with GDM randomised into an active intervention group gave birth to infants with lower rate of serious perinatal complications compared to routinecare group. Kwik et al. [43] reported observational associations between untreated GDM and macrosomia, shoulder dystocia and preeclampsia. In another observational study among women treated for mild GDM, higher fasting glucose during initiation of diet therapy was associated with increased neonatal fat mass and elevated C-peptide [46]; during the last two weeks before delivery, higher fasting glucose was associated with macrosomia, large for gestational age, and elevated C-peptide [46]. Reduction of adverse outcomes with detection and treatment of even mild GDM can be cost-effective and reduces economic burden on health care [47]. The United States Preventive Services Task Force recently published their recommendation of screening all asymptomatic women for GDM after 24 weeks of gestation, in view of the moderate net benefit of GDM screening in reducing maternal and fetal complications [48].

GDM has adverse long-term consequences for both mother and offspring. Women with GDM have increased risk of developing GDM in a subsequent pregnancy [3-5] and type 2 diabetes within 5-10 years [4]. In addition, children born from pregnancies affected by glucose intolerance have higher risks for obesity and type 2 diabetes in early adult life $[3,4,7,49]$. Detection of GDM is important to help identify high-risk women and their offspring prior to the clinical onset of adverse consequences; appropriate interventions could reduce their future risk of type 2 diabetes and cardiovascular disease [50].

\section{Conclusions}

Our study suggests that universal screening for GDM should be instituted in the Singapore population, particularly for Chinese and Indian women. In the population we studied, selective screening failed to detect nearly half the women with GDM. Timely detection of even mild GDM is important to prevent adverse outcomes for both mother and offspring. The current practice of high-risk screening for GDM in most Asian countries will miss many cases and thereby hinder prevention of its short- and long-term adverse sequelae.

\section{Additional file}

Additional file 1: Table S1. Odds ratio of gestational diabetes mellitus (GDM) detection across ethnic groups using universal and high-risk screening. Table S2. Sensitivity and specificity of high-risk screening across ethnic groups.

\section{Competing interests}

PDG, KMG and YSC have received reimbursement for speaking at conferences sponsored by companies selling nutritional products. They are part of an academic consortium that has received research funding from Abbott Nutrition, Nestec and Danone.

\section{Authors' contributions}

YSC, KK and SMS obtained funding, conceived, designed and supervised the study and interpreted the data. SC did literature search, drafted the manuscript, analysed and interpreted the data. $\mathrm{HL}$ did literature search and interpreted the data, SES, YHC, JH, CL analysed and interpreted the data. PDG and KMG conceived and designed the study and interpreted the data. YSL, KHT, VSR and GYSH interpreted the data and contributed to the study design and supervised the data collection. MKSL and MSK interpreted the data. All authors critically revised the manuscript for intellectual and scientific content. All authors read and approved the final manuscsript.

\section{Authors' information}

Yap-Seng Chong and Shirong Cai joint first authors.

\section{Acknowledgment}

This work is supported by the Translational Clinical Research (TCR) Flagship Program on Developmental Pathways to Metabolic Disease funded by the National Research Foundation (NRF) and administered by the National Medical Research Council (NMRC), Singapore (NMRC/TCR/004-NUS/2008). Additional funding is provided by the Singapore Institute for Clinical Sciences - A*STAR. KMG is supported by the National Institute for Health Research through the NIHR Southampton Biomedical Research Centre and by the European Union's Seventh Framework Programme (FP7/2007-2013), project Early Nutrition under grant agreement no. 289346. We will like to acknowledge the GUSTO study group for their contribution. The study group includes Pratibha Agarwal, Arijit Biswas, Choon Looi Bong, Birit FP Broekman, Jerry Kok Yen Chan, Cornelia Yin Ing Chee, Helen Y. H Chen, Yin Bun Cheung, Audrey Chia, Amutha Chinnadurai, Chai Kiat Chng, Mary Foong-Fong Chong, Shang Chee Chong, Mei Chien Chua, Chun Ming Ding, Eric Andrew Finkelstein, Doris Fok, Marielle Fortier, Anne Eng Neo Goh, Yam Thiam Daniel Goh, Joshua J. Gooley, Wee Meng Han, Mark Hanson, Christiani Jeyakumar Henry, Chin-Ying Hsu, Hazel Inskip, Jeevesh Kapur, Ivy Yee-Man Lau, Bee Wah Lee, Ngee Lek, Sok Bee Lim, Yen-Ling Low, Iliana Magiati, Lourdes Mary Daniel, Michael Meaney, Cheryl Ngo, Krishnamoorthy Naiduvaje, Wei Wei Pang, Anqi Qiu, Boon Long Quah, Victor Samuel Rajadurai, Mary Rauff, Salome A. Rebello, Jenny L. Richmond, Anne Rifkin-Graboi, Lynette Pei-Chi Shek, Allan Sheppard, Borys Shuter, Leher Singh, Walter Stunkel, Lin Lin Su, Oon Hoe Teoh, Mya Thway Tint, Hugo P S van Bever, Rob M. van Dam, Inez Bik Yun Wong, P. C. Wong, Fabian Yap.

\section{Author details}

'Department of Obstetrics \& Gynaecology, Yong Loo Lin School of Medicine, National University of Singapore, National University Health System, 1E Kent Ridge Road, NUHS Tower Block, Singapore 119228, Singapore. ${ }^{2}$ Saw Swee Hock School of Public Health, National University of Singapore, 16 Medical Drive, Singapore 117597, Singapore. ${ }^{3}$ Department of Paediatrics, Yong Loo Lin School of Medicine, National University of Singapore, National University 
Health System, 1E Kent Ridge Road, NUHS Tower Block, Singapore 119228, Singapore. ${ }^{4}$ Singapore Institute for Clinical Sciences, Agency for Science and Technology Research (A*STAR), Brenner Center for Molecular Medicine, 30 Medical Drive, Singapore 117609, Singapore. ${ }^{5}$ Department of Endocrinology, Tan Tock Seng Hospital, 11 Jalan Tan Tock Seng, Singapore 308433, Singapore. ${ }^{6}$ Office of Clinical Sciences, Duke-NUS Graduate Medical School, 8 College Road, Singapore 169857, Singapore. ${ }^{7}$ Biostatistics Unit, Yong Loo Lin School of Medicine, National University of Singapore, National University Health System, $1 E$ Kent Ridge Road, NUHS Tower Block, Singapore 119228, Singapore. ${ }^{8}$ Department of Obstetrics and Gynaecology, KK Women's and Children's Hospital, 100 Bukit Timah Road, Singapore 229899, Singapore. ${ }^{9}$ Department of Neonatology, KK Women's and Children's Hospital, 100 Bukit Timah RoadSingapore 229899, Singapore. ${ }^{10}$ Department of Maternal Fetal Medicine, KK Women's and Children's Hospital, 100 Bukit Timah RoadSingapore 229899, Singapore. ${ }^{11}$ Department of Epidemiology, Biostatistics and Occupational Health and Department of Pediatrics, McGill University Faculty of Medicine, 845 Rue Sherbrooke Ouest, Montréal, QC H3A OG4, Canada. ${ }^{12}$ Liggins Institute, University of Auckland, Auckland 1142, New Zealand. ${ }^{13}$ Medical Research Council Lifecourse Epidemiology Unit, Southamptom SO16 6YD, UK. ${ }^{14} \mathrm{NIHR}$ Southampton Biomedical Research Centre, University of Southampton and University Hospital Southampton NHS Foundation Trust, Southampton SO16 6YD, UK.

Received: 10 March 2014 Accepted: 23 September 2014 Published: 2 October 2014

\section{References}

1. Landon MB, Gabbe SG: Gestational diabetes mellitus. Obstet Gynecol 2011, 118(6):1379-1393.

2. Inkster ME, Fahey TP, Donnan PT, Leese GP, Mires GJ, Murphy DJ: Poor glycated haemoglobin control and adverse pregnancy outcomes in type 1 and type 2 diabetes mellitus: systematic review of observational studies. BMC Pregnancy Childbirth 2006, 6:30

3. Bloomgarden ZT: American diabetes association 60th scientific sessions, 2000: diabetes and pregnancy. Diabetes Care 2000, 23(11):1699-1702.

4. Farrell M: Improving the care of women with gestational diabetes. Am J Mat Child Nurs 2003, 28(5):301-305.

5. Gabbe SG, Landon MB, Warren-Boulton E, Fradkin J: Promoting health after gestational diabetes: a National Diabetes Education Program call to action. Obstet Gynecol 2012, 119(1):171-176.

6. Bellamy L, Casas JP, Hingorani AD, Williams D: Type 2 diabetes mellitus after gestational diabetes: a systematic review and meta-analysis. Lancet 2009, 373(9677):1773-1779.

7. Catalano PM, Kirwan JP, Haugel-de Mouzon S, King J: Gestational diabetes and insulin resistance: role in short- and long-term implications for mother and fetus. J Nutr 2003, 133(5 Suppl 2):1674S-1683S.

8. Hillier TA, Pedula KL, Schmidt MM, Mullen JA, Charles MA, Pettitt DJ: Childhood obesity and metabolic imprinting: the ongoing effects of maternal hyperglycemia. Diabetes Care 2007, 30(9):2287-2292.

9. Reece EA, Leguizamon G, Wiznitzer A: Gestational diabetes: the need for a common ground. Lancet 2009, 373(9677):1789-1797.

10. Nolan CJ, Damm P, Prentki M: Type 2 diabetes across generations: from pathophysiology to prevention and management. Lancet 2011, 378(9786):169-181

11. Scott DA, Loveman E, McIntyre L, Waugh N: Screening for gestational diabetes: a systematic review and economic evaluation. Health Technol Assess 2002, 6(11):1-161.

12. Russell MA, Carpenter MW, Coustan DR: Screening and diagnosis of gestational diabetes mellitus. Clin Obstet Gynecol 2007, 50(4):949-958

13. Ducarme G, Muratorio C, Luton D: Against universal screening for gestational diabetes mellitus. Gynecol Obstet Fertil 2008, 36(5):564-566.

14. Schmitz T: For universal screening of gestational diabetes mellitus. Gynecol Obstet Fertil 2008, 36(5):567-569

15. American College of Obstetricians and Gynecologists Committee on Practice Bulletins-Obstetrics: ACOG practice bulletin. Clinical management guidelines for obstetrician-gynecologists. Number 30, September 2001 (replaces Technical Bulletin Number 200, December 1994). Gestational diabetes. Obstet Gynecol 2001, 98(3):525-538.

16. Association AD: Standards of medical care in diabetes-2009. Diabetes Care 2009, 32(Suppl 1):S13-S61.
17. Guideline Development Group: Management of diabetes from preconception to the postnatal period: summary of NICE guidance. BMJ 2008, 336(7646):714-717.

18. Metzger BE, Gabbe SG, Persson B, Buchanan TA, Catalano PA, Damm P, Dyer AR, Leiva A, Hod M, Kitzmiler JL, Lowe LP, McIntyre HD, Oats JJ, Omori Y, Schmidt MI: International association of diabetes and pregnancy study groups recommendations on the diagnosis and classification of hyperglycemia in pregnancy. Diabetes Care 2010, 33(3):676-682.

19. Corcoy R, Garcia-Patterson A, Pau E, Pascual E, Altirriba O, Adelantado JM, de Leiva A: Is selective screening for gestational diabetes mellitus worthwhile everywhere? Acta Diabetol 2004, 41(4):154-157.

20. Di Cianni G, Volpe L, Casadidio I, Bottone P, Marselli L, Lencioni C, Boldrini A, Teti G, Del Prato S, Benzi L: Universal screening and intensive metabolic management of gestational diabetes: cost-effectiveness in Italy. Acta Diabetol 2002, 39(2):69-73.

21. Cheung NW, Wasmer G, Al-Ali J: Risk factors for gestational diabetes among Asian women. Diabetes Care 2001, 24(5):955-956.

22. Jenum AK, Morkrid K, Sletner L, Vangen S, Torper JL, Nakstad B, Voldner N, Rognerud-Jensen OH, Berntsen S, Mosdol A, Skrivarhaug T, Vardal MH, Holme I, Yajnik CS, Birkeland KI: Impact of ethnicity on gestational diabetes identified with the WHO and the modified International Association of Diabetes and Pregnancy Study Groups criteria: a population-based cohort study. Eur J Endocrinol/Eur Fed Endocrinol Soc 2012, 166(2):317-324.

23. United Nations DoEaSA, Population Division: World population prospects: The 2010 revision, Highlights and Advance Tables. Working Paper No ESA/PNP 2011, 220(220):1-164.

24. Soh SE, Tint MT, Gluckman PD, Godfrey KM, Rifkin-Graboi A, Chan YH, Stunkel W, Holbrook JD, Kwek K, Chong YS, Saw SM: Cohort profile: growing up in Singapore towards healthy outcomes (GUSTO) birth cohort study. Int J Epidemio/ 2013, doi:10.1093/ije/dyt125.

25. Wong L, Tan AS: The glucose challenge test for screening gestational diabetes in pregnant women with no risk factors. Singap Med J 2001, 42(11):517-521.

26. Alberti KG, Zimmet PZ: Definition, diagnosis and classification of diabetes mellitus and its complications. Part 1: diagnosis and classification of diabetes mellitus provisional report of a WHO consultation. Diabetic Med 1998, 15(7):539-553.

27. Tan $P C$, Ling LP, Omar SZ: Screening for gestational diabetes at antenatal booking in a Malaysian university hospital: the role of risk factors and threshold value for the $50-g$ glucose challenge test. Aust N Z J Obstet Gynaecol 2007, 47(3):191-197.

28. Wagaarachchi PT, Fernando L, Premachadra P, Fernando DJ: Screening based on risk factors for gestational diabetes in an Asian population. J Obstetr Gynaecol 2001, 21(1):32-34.

29. Wong W: Gestational diabetes mellitus in five ethnic groups: a comparison of their clinical characteristics. Diabet Med 2012, 29(3):366-371.

30. Monnier L, Lapinski H, Colette C: Contributions of fasting and postprandial plasma glucose increments to the overall diurnal hyperglycemia of type 2 diabetic patients: variations with increasing levels of $\mathrm{HbA}(1 \mathrm{c})$. Diabetes Care 2003, 26(3):881-885

31. Chu SY, Callaghan WM, Kim SY, Schmid CH, Lau J, England LJ, Dietz PM: Maternal obesity and risk of gestational diabetes mellitus. Diabetes Care 2007, 30(8):2070-2076.

32. Di Cianni G, Volpe L, Lencioni C, Miccoli R, Cuccuru I, Ghio A, Chatzianagnostou K, Bottone P, Teti G, Del Prato S, Benzi L: Prevalence and risk factors for gestational diabetes assessed by universal screening. Diabetes Res Clin Pract 2003, 62(2):131-137.

33. Kabiru W, Raynor BD: Obstetric outcomes associated with increase in BMI category during pregnancy. Am J Obstet Gynecol 2004, 191(3):928-932.

34. Torloni MR, Betran AP, Horta BL, Nakamura MU, Atallah AN, Moron AF, Valente $\mathrm{O}$ : Prepregnancy BMI and the risk of gestational diabetes: a systematic review of the literature with meta-analysis. Obes Rev 2009, 10(2):194-203.

35. Misra A, Khurana L: Obesity-related non-communicable diseases: South Asians vs White Caucasians. Int J Obes (Lond) 2011, 35(2):167-187.

36. Khoo CM, Sairazi S, Taslim S, Gardner D, Wu Y, Lee J, van Dam RM, Shyong Tai E: Ethnicity modifies the relationships of insulin resistance, inflammation, and adiponectin with obesity in a multiethnic Asian population. Diabetes Care 2011, 34(5):1120-1126.

37. Tai ES, Lim SC, Chew SK, Tan BY, Tan CE: Homeostasis model assessment in a population with mixed ethnicity: the 1992 Singapore National Health Survey. Diabetes Res Clin Pract 2000, 49(2-3):159-168. 
38. Diagnostic Criteria and Classification of Hyperglycaemia First Detected in Pregnancy. http://apps.who.int/iris/bitstream/10665/85975/1/ WHO_NMH_MND_13.2_eng.pdf.

39. Martin PL, Abella Ml, Kuptsch C: Managing Labor Migration in the Twenty-First Century. New Haven: Yale University Press; 2006.

40. Crowther CA, Hiller JE, Moss JR, McPhee AJ, Jeffries WS, Robinson JS: Effect of treatment of gestational diabetes mellitus on pregnancy outcomes. N Engl I Med 2005, 352(24):2477-2486.

41. Fadl HE, Ostlund IK, Magnuson AF, Hanson US: Maternal and neonatal outcomes and time trends of gestational diabetes mellitus in Sweden from 1991 to 2003. Diabetic Med 2010, 27(4):436-441.

42. Fan ZT, Yang HX, Gao XL, Lintu H, Sun WJ: Pregnancy outcome in gestational diabetes. Int J Gynaecol Obstetr 2006, 94(1):12-16.

43. Kwik M, Seeho SK, Smith C, McElduff A, Morris JM: Outcomes of pregnancies affected by impaired glucose tolerance. Diabetes Res Clin Pract 2007, 77(2):263-268.

44. Landon MB, Mele L, Spong CY, Carpenter MW, Ramin SM, Casey B, Wapner RJ, Varner MW, Rouse DJ, Thorp JM Jr, Sciscione A, Catalano P, Harper M, Saade G, Caritis SN, Sorokin Y, Peaceman AM, Tolosa JE, Anderson GD: The relationship between maternal glycemia and perinatal outcome. Obstet Gynecol 2011, 117(2 Pt 1):218-224.

45. Shand AW, Bell JC, McElduff A, Morris J, Roberts CL: Outcomes of pregnancies in women with pre-gestational diabetes mellitus and gestational diabetes mellitus; a population-based study in New South Wales, Australia, 1998-2002. Diabetic Med 2008, 25(6):708-715.

46. Durnwald CP, Mele L, Spong CY, Ramin SM, Varner MW, Rouse DJ, Sciscione A, Catalano P, Saade G, Sorokin Y, Tolosa JE, Casey B, Anderson GD: Glycemic characteristics and neonatal outcomes of women treated for mild gestational diabetes. Obstet Gynecol 2011, 117(4):819-827.

47. Ohno MS, Sparks TN, Cheng YW, Caughey AB: Treating mild gestational diabetes mellitus: a cost-effectiveness analysis. Am J Obstet Gynecol 2011 205(3):282. e281-287.

48. Moyer VA: Screening for gestational diabetes mellitus: U.S. preventive services task force recommendation statement. Ann Intern Med 2014, 160(6):414-420.

49. Dornhorst A, Girling JC: Management of gestational diabetes mellitus. N Engl J Med 1995, 333(19):1281-1283.

50. Retnakaran R: Glucose tolerance status in pregnancy: a window to the future risk of diabetes and cardiovascular disease in young women. Curr Diabetes Rev 2009, 5(4):239-244.

doi:10.1186/1471-2393-14-345

Cite this article as: Chong et al.: Ethnic differences translate to inadequacy of high-risk screening for gestational diabetes mellitus in an Asian population: a cohort study. BMC Pregnancy and Childbirth 2014 14:345.

\section{Submit your next manuscript to BioMed Central and take full advantage of:}

- Convenient online submission

- Thorough peer review

- No space constraints or color figure charges

- Immediate publication on acceptance

- Inclusion in PubMed, CAS, Scopus and Google Scholar

- Research which is freely available for redistribution 